\title{
Spectrophotometric determining of caffeine content in the selection of teas, soft and energy drinks available on the Croatian market
}

\author{
1,*Vuletić, N., ${ }^{2}$ Bardić, L. and ${ }^{1}$ Odžak, R. \\ ${ }^{1}$ Department of Chemistry, Faculty of Science, University of Split, R. Boškovića 33, 21000 Split, Croatia \\ ${ }^{2}$ University Department of Forensic Sciences, University of Split, R. Boškovića 33, 21000 Split, Croatia
}

\section{Article history: \\ Received: 4 September 2020 \\ Received in revised form: 19 \\ October 2020 \\ Accepted: 17 December 2020 \\ Available Online: 3 April \\ 2021}

\section{Keywords:}

Caffeine,

Tea,

Soft drinks,

Energy drinks,

Spectrophotometry

DOI:

https://doi.org/10.26656/fr.2017.5(2).482

\begin{abstract}
This study aimed to determine concentrations of caffeine in the samples of the selected brands of teas, soft carbonated and energy drinks that are commercially available on the Croatian market. Quantitative analysis of caffeine content in the chosen beverage samples was done with UV/Vis spectrophotometric method. Chloroform was used as the solvent and concentrations of caffeine were measured at the wavelength of $274 \mathrm{~nm}$ for three samples of each of the selected beverages. Among the analyzed tea samples the highest caffeine concentration was found in Franck's Black Tea (1471.021 ppm) and the lowest in Naturavita's Green Tea with Ginger (588.138 ppm). Between the analyzed carbonated soft drinks, the highest caffeine concentration was measured in Fresh Cola (136.036 ppm) and the lowest in Sky Cola (48.198 ppm). The highest caffeine concentration in the analyzed energy drink samples was measured in Hell energy drink (394.670 ppm) while the lowest was in Coca Cola Energy drink (173.574 ppm). The results of this study gave preliminary information about caffeine levels in often consumed teas, carbonated soft drinks and energy drinks in Croatia. The caffeine content in the analyzed teas and drink samples in this study was under the allowed one except for Red Bull and Hell.
\end{abstract}

\section{Introduction}

Caffeine is a bitter white crystalline alkaloid from the methylxanthine group. The systematic name of caffeine is 1,3,7-trimethylxanthine. The structure of caffeine is given in Figure 1. The molar mass of caffeine is $194,19 \mathrm{~g} / \mathrm{mol}$ and its density is $1,2 \mathrm{~g} / \mathrm{mL}$. It has low solubility in cold water. Its solubility is somewhat better in hot water, ethyl-acetate, pyrimidine, pyrrole and acetone. It is very well dissolved in ether, petroleum ether, benzene and chloroform (Schlager et al., 2006).

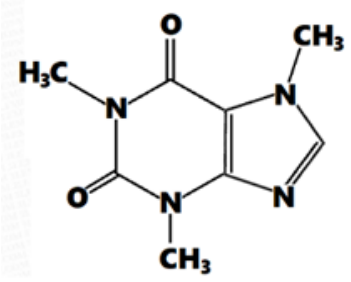

Figure 1. Chemical structure of caffeine

Caffeine can be found in the leaves and seeds of different plants. Most commonly it is derived from coffee, cocoa or cola seeds and tea leaves. About 60 species of plants native to Africa, East Asia and South America contain caffeine which helps them against predator insects (Caballero et al., 2015). Usually, it is isolated from coffee beans, tea leaves and cola seeds (Andrews et al., 2007).

Tea is a big source of caffeine. Some types of tea such as black or oolong tea contain higher concentrations of caffeine compared with other types of tea such as green tea (Wanyika et al., 2010). Tea originates from China where it was/is used for medical purposes. It is produced from Camellia sinensis, a plant that is native to China and India and is cultivated in tropical and subtropical areas (Atomssa and Gholap, 2011). Tea contains flavonoids and has anti-inflammatory and neuroprotective properties (Maidon et al., 2012). Differences in tea types are consequences of different geographical origin, cultivation conditions and ways of processing. Green tea is the most popular tea in Asia. It is made of unfermented leaves, tastes mild and contains a large amount of caffeine. Black tea has a rich bitter taste and is prepared with fermented leaves. It contains the highest amounts of caffeine and polyphenols such as flavonoids. Flavonoids are important because of their effect against harmful agents (Sharangi, 2009).

Caffeine is the most common component of soft 
drinks like colas. It is deliberately added to these drinks because of their taste and to cause the addiction to a drink (Khalid et al., 2016). The caffeine content in soft drinks varies depending on drink type. It can be from 10 to $50 \mathrm{mg}$ of caffeine per serving portion (Violeta et al., 2010). US Food and Drug Administration restricted the maximum amount of caffeine in carbonated drinks to 6 $\mathrm{mg} / \mathrm{oz}$. The allowed amount of caffeine in soft drinks can be in the range of 30 to $72 \mathrm{mg} / 335 \mathrm{~mL}(12 \mathrm{oz})$ or 8,45 to $20,28 \mathrm{mg} / 100 \mathrm{~mL}$ (Amos-Tautua et al., 2014).

Energy drinks such as Red Bull, Monster etc. are non -alcoholic drinks that contain caffeine and herbal extracts of guarana, ginseng or Ginkgo biloba, B vitamins, amino acid derivatives like carnitine and sugar derivatives (ribose, glucuronolactone) (Boyle and Castillo, 2006). It has been noted that there is 80 to $350 \mathrm{mg}$ of caffeine and $35 \mathrm{~g}$ of processed sugar in 8-oz per serving portion of energy drink (Clauson et al., 2008). One can of commercially available energy drink contains 80 to 280 $\mathrm{mg}$ of caffeine depending on the size of a can (Weinberg and Bealer, 2004).

Drinks which contain caffeine like coffee, tea, soft and energy drinks are very popular. Caffeine is the most frequently used psychoactive matter worldwide. Adults take $3 / 4$ of a daily amount of caffeine through coffee. Usually, a cup of coffee contains $100 \mathrm{mg}$ of caffeine. Even decaf coffee is not without caffeine. It can contain $12 \mathrm{mg}$ of caffeine (Frary et al., 2005). A cup of tea contains $85 \mathrm{mg}$ of caffeine. The effect of caffeine on the human body can appear 15 minutes after ingestion and can last for hours. Children get caffeine from soft and energy drinks in the fast-growing beverage market (Kamijo et al., 1999).

Most people do not go through mood changes with less than $300 \mathrm{mg}$ of caffeine taken. Sleep is more sensitive and can be disturbed with $200 \mathrm{mg}$ of caffeine (Frary et al., 2005). Dehydration is a big drawback in caffeine consummation because of its diuretic action (Lau et al., 1992). Caffeine creates strong addiction, increases the amount of stress, accelerates ageing and the appearance of wrinkles (Mrvos et al., 1992). Caffeine is metabolized in the liver through the P450 oxidase enzyme system and each of these metabolites has its effect on the body. Paraxantine (84\%) increases the amount of free fat acids in blood plasma. Theobromine $(12 \%)$ increases urine volume. Theophylline (4\%) releases smooth muscles of bronchi and is used to treat asthma (Newton et al., 1981).

Ingestion of 100-200 mg of caffeine causes increased alertness and vigilance, faster and more clear thought flow, increased focus and better general body coordination (Stranton and Gray, 1995). Acute caffeine overdose, usually more than $250 \mathrm{mg}$ (more than 2-3 cups of cooked coffee) can lead to the state of overstimulated CNS and caffeine intoxication as well (Khalid et al., 2016).

There are many advantages of caffeine consumption. It is used to reduce physical fatigue and for its medical characteristics also (Amos-Tautua et al., 2014). It can be used in combination with certain pain relievers for treating migraines (Khalid et al., 2016). In the big research that included 217883 people were shown that there was lower kidney stones formation if caffeine was consumed (Ferraro et al., 2013). Caffeine can induce hair growth, protects from eyelid spasm, cataract and prevents skin cancer. It can reduce the risk of some types of cancer like liver cancer or colon cancer. It reduces the risk of Type 2 diabetes and Parkinson's disease (Graham, 1978).

There are many disadvantages to caffeine. It can cause anxiety if taken in the amount of $300 \mathrm{mg}$ or more (Smith, 2002). Caffeine increases the concentration of dopamine in the brain and that eases depression. It accelerates bone tissue loss in postmenopausal older women. It can cause auditory hallucinations. If in overdose, caffeine causes high blood pressure, restlessness, insomnia, accelerated pulse, nausea, increased urination, cardiac palpitations, gastrointestinal disorders (diarrhea) and dizziness (Graham, 1978).

The main goal of this study was to determine the concentrations of caffeine in different samples of commercially available types of teas, carbonated soft drinks and energy drinks in the supermarkets in Croatia.

\section{Materials and methods}

\subsection{Chemicals}

The chemicals used in this study include caffeine standard $\left(\mathrm{C}_{8} \mathrm{H}_{10} \mathrm{~N}_{4} \mathrm{O}_{2}\right)$ from Sigma-Aldrich (SigmaAldrich Chemic GmbH, Munich, Germany), chloroform $\left(\mathrm{CHCl}_{3}\right)$ and sodium carbonate $\left(\mathrm{Na}_{2} \mathrm{CO}_{3}\right)$ obtained from Merck (Merck, Darmstadt, Germany). All reagents used in this study were of analytical grade and all solutions were prepared by using distilled water.

\subsection{Sample collection}

Different samples of black and green tea (Franck Green Tea, Franck Black Tea, Naturavita Green Tea, Naturavita Green Tea with Ginger, Agristar Green Tea, Agristar Black Tea and Orange, Dar Vitalis Eko Green Tea), soft drinks (Coca-Cola, Coca-Cola Zero, Pepsi Cola, Cockta, Fresh Cola, Fresh Cola Light, Sky Cola) and energy drinks (Red Bull, Monster Assault, Burn 
Passion Punch, Hell Strong Apple, Coca-Cola Energy) were purchased from the local markets in Croatia.

\subsection{Instrument}

The UV/Vis spectrophotometer (Secomam, UVi Light-XTD5, Ales, France) was used for the analysis of caffeine in different samples of teas, soft and energy drinks.

\subsection{Wavelength selection}

The wavelength at which caffeine absorbs maximum was determined by scanning the range of 190-400 nm. The wavelength at which caffeine absorbs maximum was found to be $274 \mathrm{~nm}$ which was selected for further analyses. The same wavelength was reported by Rehman and Ashraf, 2017 (Rehman et al., 2017).

\subsection{Calibration solutions preparation}

Caffeine stock solution (100 ppm) was prepared by dissolving $0.01 \mathrm{~g}$ of recrystallized caffeine in $100 \mathrm{~mL}$ of chloroform in the volumetric flask. From the caffeine stock solution following dilutions were prepared: $1 \mathrm{ppm}$, $5 \mathrm{ppm}, 10 \mathrm{ppm}, 15 \mathrm{ppm}, 20 \mathrm{ppm}$ and $25 \mathrm{ppm}$. Their absorbances were measured at the wavelength of $274 \mathrm{~nm}$ in quartz cuvettes three times for each dilution. Average values of measured absorbances are given in Table 1 . The absorbance values were used to make the calibration line for caffeine content analysis as shown in Figure 2.

Table 1. Absorbance of calibration solutions of caffeine

\begin{tabular}{ccc}
\hline No & Concentration $(\mathrm{ppm})$ & Absorbance \\
\hline 1 & 1 & 0.143 \\
2 & 5 & 0.437 \\
3 & 10 & 0.644 \\
4 & 15 & 0.776 \\
5 & 20 & 1.079 \\
6 & 25 & 1.319 \\
\hline
\end{tabular}

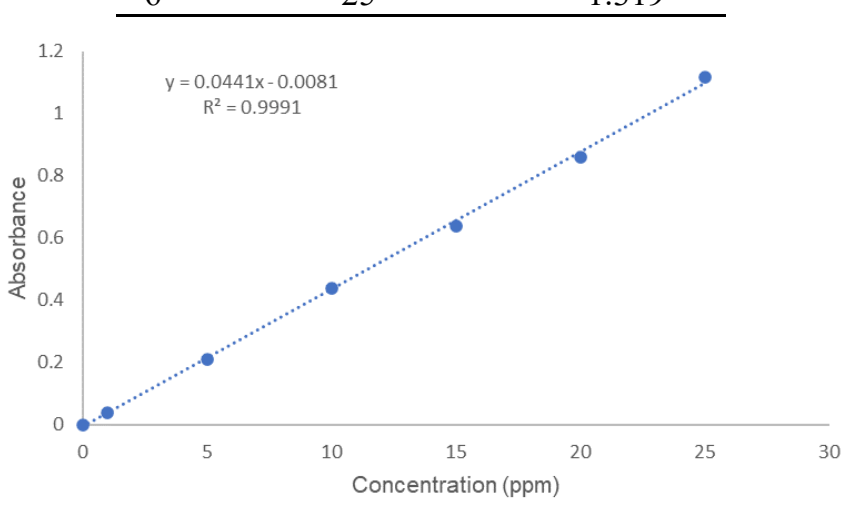

Figure 2. Standard calibration curve of caffeine

\subsection{Extraction of caffeine from black and green tea samples and preparation of the sample solutions}

Exactly $2 \mathrm{~g}$ of each tea sample was weighed. $20 \mathrm{~mL}$ of distilled water was added to the sample and the content was heated and then boiled for 10 mins. A total of $2 \mathrm{~g}$ of sodium carbonate was added to each sample for precipitating tannins. Samples were filtered and filtrates were concentrated to $5 \mathrm{~mL}$ by heating. From the given volume caffeine was extracted by adding $5 \mathrm{~mL}$ of chloroform in the separatory funnel. Caffeine was extracted by stirring in the separatory funnel for a few minutes. The lower caffeine-containing layer was separated and analyzed for caffeine content with UV/Vis spectrophotometer. $0.1 \mathrm{~mL}$ of each tea extract was mixed with $10 \mathrm{~mL}$ of chloroform and placed in a quartz cuvette. Absorbance was measured at $274 \mathrm{~nm}$. Three samples of each brand of tea were analyzed for caffeine content. Average values are given in Table 2.

Table 2. Caffeine contents of tea and beverage samples

\begin{tabular}{|c|c|c|c|}
\hline $\begin{array}{l}\text { Sample } \\
\text { type }\end{array}$ & Sample name & Mark & $\begin{array}{c}\text { Caffeine } \\
\text { concentration } \\
(\mathrm{ppm})\end{array}$ \\
\hline \multirow{7}{*}{ Teas } & Franck Green Tea & $\mathrm{T} 1$ & 1209.76 \\
\hline & Franck Black Tea & $\mathrm{T} 2$ & 1471.021 \\
\hline & Naturavita Green Tea & $\mathrm{T} 3$ & 904.204 \\
\hline & $\begin{array}{c}\text { Naturavita Green Tea } \\
\text { with Ginger }\end{array}$ & $\mathrm{T} 4$ & 588.138 \\
\hline & Agristar Green Tea & $\mathrm{T} 5$ & 1423.724 \\
\hline & $\begin{array}{l}\text { Agristar Black Tea } \\
\text { and Orange }\end{array}$ & T6 & 1413.964 \\
\hline & $\begin{array}{c}\text { Dar Vitalis Eko Green } \\
\text { Tea }\end{array}$ & $\mathrm{T} 7$ & 625.676 \\
\hline \multirow{7}{*}{$\begin{array}{l}\text { Carbonated } \\
\text { soft drinks }\end{array}$} & Coca-Cola & SD1 & 102.252 \\
\hline & Coca-Cola Zero & SD2 & 95.12 \\
\hline & Pepsi Cola & SD3 & 86.486 \\
\hline & Fresh Cola & SD4 & 136.036 \\
\hline & Fresh Cola Light & SD5 & 49.7 \\
\hline & Sky Cola & SD6 & 48.198 \\
\hline & Cockta & SD7 & 0 \\
\hline \multirow{5}{*}{$\begin{array}{l}\text { Energy } \\
\text { drinks }\end{array}$} & Red Bull & ED1 & 350.751 \\
\hline & Monster & ED2 & 317.342 \\
\hline & Hell & ED3 & 394.67 \\
\hline & Burn & ED4 & 252.778 \\
\hline & Coca-Cola Energy & ED5 & 173.574 \\
\hline
\end{tabular}

2.7 Extraction of caffeine from soft and energy drinks and preparation of the sample solutions

Soft and energy drink samples were heated and then boiled for 10 minutes to remove $\mathrm{CO}_{2}$. The samples were left to cool to room temperature. A total of $10 \mathrm{~mL}$ of each sample was taken and placed in the separatory funnel. $1 \mathrm{~mL}$ of $20 \%(\mathrm{w} / \mathrm{v})$ sodium carbonate solution and $5 \mathrm{~mL}$ of chloroform was added to each sample. Caffeine was extracted by stirring the funnel for a few minutes and then the lower layer was separated. An aliquot $(0.1 \mathrm{~mL})$ of each extract was mixed with $5 \mathrm{~mL}$ of chloroform and placed in a quartz cuvette. The absorbance was measured at $274 \mathrm{~nm}$. Three samples of 
each brand of drink were analyzed for caffeine content. Average values are given in Table 2.

\section{Results and discussion}

The standard linear calibration curve obtained from the standard solutions of caffeine is presented in Figure 2. It showed a good linear relation between the absorbance and concentrations of standard solutions.

Caffeine content levels in tea, carbonated soft drink and energy drink samples are presented and illustrated in Table 2 and Figure 3.

The concentration of caffeine in tea samples was in the range of 588.138 to $1471.021 \mathrm{ppm}$ with an average value of $1090.927 \mathrm{ppm}$. The highest caffeine concentration was measured in Franck's Black Tea and the lowest was measured in Natura Vita's Green Tea with Ginger.

The concentration of caffeine in carbonated soft drinks was in the range of 48.148 to $136.036 \mathrm{ppm}$ with an average value of $86.299 \mathrm{ppm}$. The highest concentration of caffeine was measured in Fresh Cola and the lowest in Sky Cola. There was not any caffeine present in the samples of soft drink Cockta that were analyzed in this study.

Caffeine concentrations that were measured in energy drink samples were in the range of 173.574 to $394.670 \mathrm{ppm}$ with an average value of $297.823 \mathrm{ppm}$. The highest caffeine concentration was measured in Hell energy drink while the lowest was measured in samples of Coca-Cola Energy.

The caffeine content in tea depends on the environmental conditions during the growth of the plant just as of the type of the species (Heckman et al., 2010).

The caffeine content in carbonated soft drinks around the world varies depending on the type of brand. US Food and Drug Administration (FDA) has limited the maximum amount of caffeine in soft drinks to $200 \mathrm{ppm}$.
It is visible in the present study that the caffeine content in analyzed carbonated soft drinks is under the allowed one. It is observed that the caffeine concentrations in the energy drinks are higher than the caffeine concentrations in the carbonated soft drinks (Gerald et al., 2014).

According to the Ordinance on food additives of the Ministry of Health and Welfare in Croatia, the maximum allowed amount of caffeine in soft carbonated drinks is $150 \mathrm{mg} / \mathrm{L}$ while the maximum allowed amount of caffeine in energy drinks is $320 \mathrm{mg} / \mathrm{L}$ (Narodne Novine 173, 2004).

None of the analyzed tea samples except Franck's had a caffeine content mark on the packaging.

The results of this study show that the concentrations of caffeine in the analyzed soft carbonated drinks from the Croatian local markets were lower than the maximum allowed one. Since caffeine is an addictive substance and when consumed can cause different health concerns, it would be appropriate that the amount of caffeine was specified on the labels of all carbonated caffeinecontaining drinks. None of the carbonated drinks analyzed in this study was labelled so. Labels only contained information that drinks contain caffeine.

All energy drinks were labeled with a maximum allowed concentration of caffeine which was $320 \mathrm{mg} / \mathrm{L}$, except the energy drink Hell which was labeled with 384 $\mathrm{mg} / \mathrm{L}$ of caffeine. Concentrations of caffeine in energy drinks measured in this study were lower than the one specified on their labels for all of the analyzed drinks except Red Bull and Hell which shown slightly higher concentrations of caffeine than those labels specified.

According to the European Food Safety Authority (EFSA) (2015), single doses of caffeine that do not raise safety concerns recommended for adults are up to 200 $\mathrm{mg}$. About $3 \mathrm{mg}$ per kilogram of body weight $(\mathrm{mg} / \mathrm{kg}$ bw) are generally appropriate for a healthy adult population. Single doses of $100 \mathrm{mg}$ of caffeine (about $1.4 \mathrm{mg} / \mathrm{kg}$ bw) especially if consumed before bedtime in

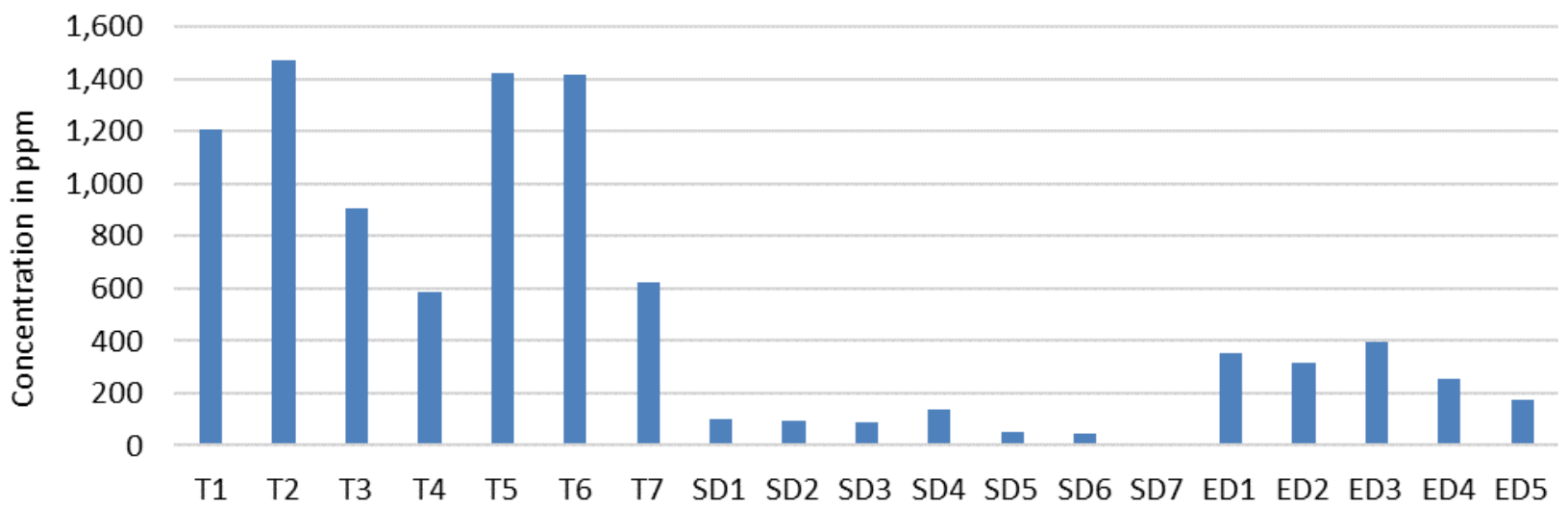

Figure 3. Chart showing caffeine content in the tea and beverage samples 
some adults may affect sleep. When healthy adults consume caffeine at a dose of $400 \mathrm{mg}$ throughout the day (about $5.7 \mathrm{mg} / \mathrm{kg}$ bw per day) they do not need to worry about safety. For pregnant women, EFSA recommends that caffeine intakes from all sources should be up to 200 mg per day consumed throughout the day. A safety level of $3 \mathrm{mg} / \mathrm{kg}$ bw of caffeine is also recommended for children and adolescents. A cup of black tea $(220 \mathrm{~mL})$ approximately contains $50 \mathrm{mg}$ of caffeine so one could consume up to 4 cups per day. Since caffeine content depends on the type of tea and since portion size varies within and between countries one should be careful with caffeine intakes.

\section{Conclusion}

$\mathrm{UV} / \mathrm{Vis}$ spectrophotometric method applied in this study for the quantitative analysis of the caffeine concentrations in tea and drink samples is sensitive, precise and correct. Additional advantages of this method are that it is inexpensive as well as easy to perform. Despite the relatively small number of the analyzed samples, the results of this study gave a preliminary information about the caffeine content often consumed in teas, soft and energy drinks in Croatia.

The results of the current study led to a conclusion that the caffeine content should be indicated on the product labels especially due to the great popularity and easy accessibility of caffeine-containing drinks. Since caffeine can be a cause for potential health concerns, precise quantities stated on the labels of caffeinated beverages should be highlighted in the interest of those who drink them. It is necessary to work on raising awareness among those who drink caffeinated beverages about the amounts of caffeine they consume.

\section{Conflict of interest}

The authors declare no conflict of interest.

\section{Acknowledgments}

This study was supported by the Ministry of Science and Education of the Republic of Croatia as a part of Multiannual Financing intended for institutions.

\section{References}

Amos-Tautua, B., Martin, W. and Diepreye, E.R.E. (2014). Ultra-violet spectrophotometric determination of caffeine in soft and energy drinks available in Yenagoa, Nigeria. Advance Journal of Food Science and Technology, 6(2), 155-158. https:// doi.org/10.19026/ajfst.6.2

Andrews, K., Schweitzer, A., Zhao, C., Holden, J.M.,
Roseland, J.M., Brandt, M., Dwyer, J.T., Picciano, M.F., Saldanha, L.G., Fisher, K.D., Yetley, E., Betz, J.M. and Douglass, L. (2007). The caffeine content of dietary supplements commonly purchased in the US: analysis of 53 products having caffeine containing ingredients. Analytical and Bioanalytical Chemistry, 389(1), 231-239. https://doi.org/10.1007/ s00216-007-1437-2

Atomssa, T. and Gholap, A.V. (2011). Characterization of caffeine and determination of caffeine in tea leaves using UV-Visible spectrometer. African Journal of Pure and Applied Chemistry, 5(1), 1-8.

Boyle, M. and Castillo, V.D. (2006). Monster on the loose. Fortune, 154, 116-122.

Caballero, B., Finglas, P. and Toldra, F. (2015). Encyclopedia of Food and Health, p. 561. USA: Elsevier Science.

Clauson, K.A., Shields, K.M., McQueen, C.E. and Persad, N. (2008). Safety issues associated with commercially available energy drinks. Journal of the American Pharmacist Association, 48(3), e55-e67. https://doi.org/10.1331/JAPhA.2008.07055

European Food Safety Authority (EFSA) Panel on Dietetic Products, Nutrition and Allergies. (2015). Scientific opinion on the safety of caffeine. EFSA Journal, 13(5), 4102. https://doi.org/10.2903/ j.efsa.2015.4102

Ferraro, P.M., Taylor, E.N., Gambaro, G. and Curhan, G.C. (2013). Soda and other beverages and the risk of kidney stones. Clinical Journal of American Society of Nephrology, 8(8), 1389-1395. https://doi.org/10.2215/CJN.1166111

Frary, C.D., Johnson, R.K. and Wang, M.Q. (2005). Food sources and intakes of caffeine in the diets of persons in the Unated States. Journal of American Dietetic Association, 105(1), 110-113. https:// doi.org/10.1016/j.jada.2004.10.027

Gerald, I., Arthur, D.E. and Adedayo, A. (2014). Determination of caffeine in beverages: a review. American Journal of Engineering Research, 3(8), 124-137.

https://doi.org/10.1016/ j.petrol.2014.09.036

Graham, D.M. (1978). Caffeine - It's identity, dietary sources, intake and biological effects. Nutrition Reviews, 36(4), 97-102. DOI: https:// doi.org/10.1111/j.1753-4887.1978.tb03717.x

Heckman, M.A., Weil, J. and Gonzales de Mejia, E. (2010). Caffeine (1,3,7 trimethylxanthine) in foods: a comprehensive review on consumption, functionality, safety and regulatory matters. Journal of Food Science 75(3), R77-R87. https:// doi.org/10.1111/j.1750-3841.2010.01561.x 
Kamijo, Y., Soma, K., Asari, Y. and Ohwada, T. (1999). Severe rhabdomyolysis following massive ingestion of oolong tea: caffeine intoxication with coexisting hyponatremia. Veterinary and Human Toxicology, 41(6), 381-383.

Khalid, A., Ahmad, S., Raza, H., Batool, M., Khan Lodhi, R., Tul Ain, Q. and Naseer, F. (2016). Determination of caffeine in soft and energy drinks available in market by using UV/Visible spectrophotometer. Family Medicine and Medical Science Research, 5, 4. https://doi.org/10.4172/23274972.1000206

Lau, O.W., Luk, S.F., Cheng, O.M. and Chiu, T.P.Y. (1992). Background-correction methods for the determination of caffeine in beverages, coffee and tea by using second-derivative ultraviolet spectrophotometry. Analyst, 4, 777- 783. DOI: https://doi.org/10.1039/an9921700777

Maidon, A.B.M.A., Mansoer, A.O. and Sulistyarti, H. (2012). Study of various solvents for caffeine determination using UV Spectrophotometric. Journal of Applied Sciences Research, 8(5), 24392442.

Mrvos, R.M., Reilly, P.E., Dean, B.S. and Krenzelok, E.P. (1989). Massive caffeine ingestion resulting in death. Veterinary and Human Toxicology, 31(6), 571 -572 .

Narodne Novine 173 (2004). Food Act. Retrieved on May 10, 2020 from NN website: https://narodnenovine.nn.hr/clanci/sluzbeni/dodatni/314185.htm.

Newton, R., Broughton, L.J., Lind, M.J., Morrison, P.J., Rogers, H.J. and Bradbrook, I.D. (1981). Plasma and salivary pharmacokinetics of caffeine in man. European Journal of Clinical Pharmacology, 21, 4552. https://doi.org/10.1007/BF00609587

Rehman, R. and Ashraf, S. (2017). Analysis of caffeine contents in commercial beverages and tea samples of Pakistan using UV/Visible spectrometry. Bulgarian Chemical Communications, 49(4), 823-828. DOI: https://doi.org/10.1111/j.1750-3841.2010.01561.x

Schlager, N., Weisblatt, J., Newton, D.E. and Montney, C.B. (2006). Chemical Compounds Vol. 1. Detroit, USA: Thomson-Gale.

Sharangi, A.B. (2009). Medicinal and therapeutic potentialities of tea (Camellia sinensis L.) - a review. Food Research International, 42, 529-535. DOI: 10.1016/j.foodres.2009.01.007

Smith, A. (2002). Effects of caffeine on human behavior. Food and Chemical Toxicology, 40(9), 1243-1255. https://doi.org/10.1016/s0278-6915(02)00096-0

Stranton, C.K. and Gray, R.H. (1995). Effects of caffeine consumption on delayed conception. American
Journal of Epidemiology, 142(12), 1322-1329. https://doi.org/10.1093/oxfordjournals.aje.a117600

Violeta, N., Trandafir, I. and Ionica, M.E. (2010). Chromatographic determination of caffeine contents in soft and energy drinks available on the Romanian market. Studii si Cercetari Stiintifice Chemie si Inginerie Chemica, Biotehnologii, Industrie Alimentara, 11(3), 351- 358.

Wanyika, H.N., Gatebe, E.G., Gitu, L.M., Ngumba, E.K. and Maritim, C.W. (2010). Determination of caffeine content of tea and instant coffee brands found in Kenyan market. African Journal of Food Science, 4 (6), 353-358.

Weinberg, B.A. and Bealer, B.K. (2004). The world of caffeine: the science and culture of the world's most popular drug. 1st ed. New York, USA: Routledge. 